\title{
К ВОПРОСУ «НЕПОИМЕНОВАННОСТИ» В ИСПОЛНИТЕЛЬНОМ ПРОИЗВОДСТВЕ
}

\section{TO THE QUESTION \\ OF "NEPOIMENOVANNOSTI" IN THE ENFORCEMENT PROCEEDINGS}

N. Sheremeteva

S. Kalashnikov E. Vasilenko

Summary: The article is devoted to the study of the problems of legal regulation of unnamed forms of coercive measures in enforcement proceedings. Attention is paid to the study of the process of digitalization of public relations, developing under the influence of information technologies. Particular attention is paid to the possibility of foreclosure on electronic forms of money. The article analyzes the need to secure atypical types of enforcement measures in order to ensure the correct and timely execution of judicial acts.

Keywords: namelessness, gap in the law, enforcement measures, electronic forms of money, digitalization process.
Шереметьева Наталья Владимировна старший преподаватель, ФГБОУ ВО «Владивостокский государственный университет экономики и сервиса»,

2. Владивосток; помошник судьи, Арбитражный суд Приморского края nata-sheremet@mail.ru

Калашников Сергей Сергеевич

ФГБОУ ВО «Владивостокский государственный университет экономики и сервиса», г. Владивосток sergej_kalashnikov_99@mail.ru

Василенко Екатерина Олеговна

ФГБОУ ВО «Владивостокский государственный университет экономики и сервиса», г. Владивосток ekaterinavasilenko@list.ru

Аннотация: Статья посвящена изучению проблем правовой регламентации непоименованных форм принудительных мер в исполнительном производстве процессе. Уделяется внимание изучению процесса цифровизации общественных отношений, развивающихся под влиянием информационных технологий. Особое внимание уделено возможности обращения взыскания на электронные формы денег. Анализируется необходимость закрепления нетипичных видов мер принудительного исполнения в целях правильного и своевременного исполнения судебных актов.

Ключевые слова: непоименованность, пробел в законе, меры принудительного исполнения, электронные формы денег, процесс цифровизации. бщественно-правовые отношения в современном мире постоянно изменяются и трансформируются, выходят на новые этапы развития. При этом каждая сфера жизни человека, будучи подверженная постоянному правовому развитию, дает нам ряд нерешенных вопросов, в том числе и в исполнительном производстве, как одного из важных и заключительных этапов судебного процесса.

В данной работе хотелось бы остановиться на относительно новом явлении, которое получило название «непоименованность».

В научной литературе довольно редко можно встретить анализ такого явления как «непоименованность». Однако отдельные авторы, такие как С.И. Суслова, В.В. Лазарев, 3. Улугова затрагивали эту тему в своих научных исследованиях.

Так, С.И. Суслова сформулировала определенные аспекты, являющиеся важными для понимания термина «непоименованность» [1].

Во-первых, автор говорит о том, что «непоименован- ность» - это, прежде всего, результат отсутствия правовой регламентации.

Во-вторых, автор подчеркивает, что появление термина «непоименованность» вызвано не только реализацией принципа диспозитивности, но и гарантированными Конституцией свободами, позволяющими каждому лицу создавать новые варианты, отличающиеся правовой новизной, для защиты своих субъективных прав и законных интересов.

B-третьих, прослеживается тесная взаимосвязь понятий «непоименованность» и «пробел в законе», которая проявляется в причинности появления обоих терминов.

Необходимо отметить, что состояние непоименованности имеет место абсолютно в любой отрасли права. Такое понятие известно и исполнительному производству.

Существование термина «непоименованность» применительно к отдельным правовым явлениям можно наблюдать и на заключительной стадии судебного процесса - исполнительное производство. 
Исполнительное производство - это совокупность юридически значимых действий на заключительном этапе судебного процесса осуществляемых органами исполнительной власти в целях обеспечения исполнения требований, содержащихся в исполнительном документе.

Важно отметить, что динамику исполнительного производства невозможно представить без совершения исполнительных действий судебными приставами и иными участниками в целях достижения задач исполнительного производства.

Федеральный закон «Об исполнительном производстве» определяет исполнительные действия, как совершаемые судебным приставом действия, направленные на создание условий применения мер принудительного исполнения, а равно на понуждение должника к полному, правильному и своевременному исполнению требований, содержащихся в исполнительном документе [2]. В силу публично-правового характера данных отношений судебный пристав занимает руководящие положение, но нельзя говорить об эффективности исполнительного производства, не принимая во внимание активные действия других участников.

Взяв за основу закрепленное в законе определение исполнительных действий, можно утверждать, что законодателем справедливо было произведено разделение мер принудительного исполнения и исполнительных действий. Безусловно, представленные действия судебного пристава составляют основу исполнительного производства и находятся в тесной взаимосвязи между собой, однако назвать их тождественными нельзя. Нужно учитывать, что указанные в статье 64 исполнительные действия, направленные на создание условий применения мер принудительного исполнения, в свою очередь вторые имеют целевую направленность - исполнение требований, указанных в исполнительном документе [2].

В качестве примера, можно привести позицию Верховного суда при рассмотрении кассационной жалобы, поданной на определение судебной коллегии. Апелляционная инстанция, равно как и районный суд допустили ошибку при квалификации нетипичных или, как принято говорить, непоименованных действий судебного пристава. Ошибочное понимание представленных выше судебных инстанций заключалось в определении сущности исполнительных действий и мер принудительного исполнения. Верховный суд указал, что суд первой и апелляционной инстанции ошибочно приравнял исполнительное действие по запрету на совершение регистрационных действий в отношении квартиры, принадлежащей гражданину, к мерам принудительного исполнения [3]. Из этого можно сделать вывод, что при оценке любого действия судебного пристава, необходи- мо исходить из целей применения таких действий для успешного разграничения мер принудительного исполнения и исполнительных действий.

Несмотря на объемность числа принудительных мер, предусмотренных в статье 68 вышеуказанного закона, законодатель расширяет возможности судебного пристава, но с одной оговоркой: меры допустимы, если они предусмотрены федеральным законом или исполнительным документом.

Ситуация с исполнительными действиями, указанных в статье 64, немного иная. В статье устанавливается перечень исполнительных действий, каждый из которых соответствует принципам и связан с необходимостью обеспечить реализацию задач исполнительного производства. Этот перечень не является закрытым, что подтверждает пункт 17: « Судебный пристав-исполнитель вправе совершать иные действия, необходимые для своевременного, полного и правильного исполнения исполнительных документов» [2].

Так, например, в постановлении Пленума Верховного Суда справедливо было отмечено, что судебный пристав вправе выходит за пределы установленных в статье 64 исполнительных действий, если это требуется для полного, своевременного и правильно исполнения исполнительного документа. При этом абсолютно все исполнительные действия, не указанные в статье 64, равно как и указанные в ней, должны соответствовать основным правовым началам и задачам исполнительного производства, не нарушая законные права и интересы должника [4]. Абсолютно аналогичная позиция содержится в Апелляционном определении Верховного суда Республики Татарстан, указав, что перечень мер принудительного не является исчерпывающим. Помимо этого, Верховный суд Республики Татарстан сделал важное примечание, касающиеся правового статуса судебного пристава: в каждом конкретном случае судебный пристав действует самостоятельно в зависимости от вынесенных требовании и обстоятельств дела [5].

Представленные выше позиции, еще раз подтверждают наличие в исполнительном производстве состояния непоименованности, в данном случае затрагивающего юридически важные действия судебного пристава: исполнительные действия и меры принудительного исполнения, открытый перечень которых представлен в статье 64 и 68 соответственно.

К числу непоименованных исполнительных действий можно отнести:

1. Запрет, направленный к должнику, расходовать денежные средства, поступающие в кассу, в полном объеме с последующим перечислением на депозитный счет судебного пристава. Как было 
отмечено выше, любое исполнительное действие выступает средством обеспечения реализации в дальнейшем мер принудительного исполнения. Данное исполнительное действие не является исключением при исполнении требований, изложенных в судебном акте. Наложение подобного запрета на денежные средства должника позволяет достичь оперативности в процессе исполнения исполнительных документов.

2. Обязанность передать взыскателю ключи от жилого помещения, принадлежащего должнику. Разновидность данного исполнительного действия, равно как и представленного выше, не указана в законе, однако процедура их исполнения производится в соответствии с общими правилами исполнительного производства. С момента подачи взыскателем заявления о возбуждении исполнительного производства судебный пристав осуществляет комплекс исполнительных действий необходимых для удовлетворения требований взыскателя.

Применение мер принудительного исполнения в отличии от исполнительных действий ставится в зависимость от соблюдения двух условий: возбуждение исполнительного производства и истечение срока для добровольного исполнения требований.

В судебной практике часто встречаются ситуации, когда должники заявляют о незаконности проведения тех или иных принудительных мер судебными приставами по причине их непоименованности в законе.

Так, например, в одном из дел судебный пристав обратил взыскание на имущественное право управляющей компании, а именно на денежные средства, находящиеся на балансе управляющей компании и формируемые за счет платежей, поступающих от граждан. Служба судебных приставов, в связи с невозможностью обратить взыскание на денежные средства или иное имущество управляющей компании, вынесла альтернативное постановление, по которому предусматривалась возможность обращения взыскания на право получения платежей, поступающих от жильцов. Верховный суд представленную меру принудительного исполнения счел допустимой [6]. Ситуация, связанная с непоименованностью принудительных мер, требует особого внимания ввиду отсутствия соответствующего правового регулирования. В каждой конкретном, разрешаемом деле судам необходимо тщательно рассматривать с разных позиций непредусмотренные, но допустимые меры принудительного исполнения. Так, в рассматриваемом случае Судебной коллегией Верховного суда необходимо было указать следующие: обращение взыскания на денежные средства, находящиеся на счетах платежного агента, возможно, но в пределах денежных сумм, при- читающихся непосредственно управляющей компании. В ином случае процесс накопления средств и их дальнейшие распределение в соответствии с нуждами жильцов - утрачивает смысл. Данная оговорка очень важна в формировании основ единообразия при разрешении подобных споров.

Продолжая тему технологического развития общества, виртуальная реальность в котором охватила все сферы отношений между людьми, стоит отметить, что на сегодняшний день большое распространение получили электронные формы денег.

В связи с этим возникает вопрос - Может ли судебный пристав в исполнительном производстве воспользоваться таким непоименованным видом меры принудительного исполнения, как обращения взыскания на электронные деньги должника?

Российское законодательство пока не дает конкретного ответа на данный вопрос, но, безусловно, уже неспецифическая форма денег в повседневных отношениях применяется все чаще и, как следствие, требует соответствующего правового регулирования. Во многих научных трудах деньги определяют через призму свойственных им функций, среди которых функция расчета выступает важнейшей. Лидирующими торговыми площадками по широкому использованию электронной платежной системы выступают WebMoney и Яндексденьги. Важно отметить, что все операции, совершаемые на таких цифровых платформах, выполняются с помощью различных, характерных для той или иной платежной платформы электронной валюты, объем которой зависит от вложенных наличных денежных средств.

Несмотря на отсутствие четкого закрепления обозначенной выше меры принудительного исполнения, процедуру взыскания электронных денег можно считать допустимой. Во-первых, учитывая специфику движения денежных средств на электронных платежных платформах, проведение взыскания электронных денег во многом будет схожа с процедурой взыскания денежных средств, находящихся у третьих лиц. Посреднические операции по хранению, расчету и иные формы осуществления денежных средств клиента осуществляемые на электронных платформах, схожи с операциями, производимыми банками. Из этого следует, что электронные платформы - некий заменитель банков. Во-вторых, исходя из положений Гражданского кодекса, к объектам гражданских прав, на которые может быть обращено взыскание, относятся денежные средства (наличные и безналичные) [7]. Нестандартность электронных денег заключается лишь в том, что это еще мало изученная разновидность конвертации денежных средств лица. Таким образом, можно отметить, что электронные деньги - это вид безналичных денежных средств, на которые 
допустимо обращать взыскание.

Как видим, постепенное появление новых информационных технологий и усовершенствование старых, безусловно, со временем подтолкнет законодателя к корректировке норм в правовой системе: поспособствует усовершенствованию порядка применения мер принудительного исполнения, благодаря введению мер, отвечающих задачам исполнительного производства с учетом цифровизации современного мира; позволит ликвидировать техническую неосведомленность судейского состава, а также вызовет необходимость внедрения технического оборудования с целью проверки электронных доказательств в суде. А потому, такое явление, как непоименованность, по нашему мнению, нельзя назвать негативным.

С нашей точки зрения, возникновение новых форм непоименованности позитивно скажется на правовой системе Российской Федерации, а именно, устранит существующие пробелы и обогатит ее новыми положениями. Несмотря на то, что на данный момент тенденция допустимости непоименованных форм носит в большинстве случаев все же запретительный характер, по нашему мнению, курс на цифровизацию общественных отношений предопределит их дозволительный характер.

\section{ЛИТЕРАТУРА}

1. Суслова С.И. Непоименованность в гражданском праве: к постановке вопроса / С.И. Суслова// Учен. зап. Казан. ун-та. Сер. Гуманит. науки. - 2018. - Т. 160. - №. 2. - C. 404-414

2. 06 исполнительном производстве: Федеральный закон от 02.10.2007 № 229-Ф3 (последняя редакция) // СПС «КонсультантПлюс». - URL: http://www. consultant.ru/document/cons_doc_LAW_71450/.

3. Апелляционное определение Московского городского суда от 18 августа 2015 г. № 33-29482/15 // СПС «Гарант». - URL: https://base.garant.ru/137389617/.

4. О применении судами законодательства при рассмотрении некоторых вопросов, возникающих в ходе исполнительного производства: Постановление Пленума Верховного Суда РФ от 17 ноября 2015 г. № 50 // СПС «Гарант». - URL: https://base.garant.ru/71251222/.

5. Апелляционное определение СК по административным делам Верховный Суда Республики Татарстан от 19 октября 2015 №33-14579/2015 // СПС «Гарант». - URL: https://base.garant.ru/137563613/.

6. Обзор судебной практики Верховного Суда РФ от 13 апреля 2016 г. № 1 // СПС «Гарант». - URL: https://www.garant.ru/products/ipo/prime/doc/71275534/.

7. Гражданский кодекс: федеральный закон от 30.11.1994 № 51-Ф3 (ред. от 16.12.2019) [Электронный ресурс] // СПС «КонсультантПлюс». - Режим доступа: http://www.consultant.ru/document/cons_doc_LAW_5142/.

(c Шереметьева Наталья Владимировна (nata-sheremet@mail.ru ), Калашников Сергей Сергеевич (sergej_kalashnikov_99@mail.ru ), Василенко Екатерина Олеговна (ekaterinavasilenko@list.ru).

Журнал «Современная наука: актуальные проблемы теории и практики» 